Induction, zu erklären sucht, gehen von der Betrachtung der Wirkung einer Querschnittsfläche, in welcher viele Molecularströme umlaufen, auf einen benachbarten Magnetpol, aus. Feilitzsch erläutert, wie man einen solchen Querschnitt ersetzen könne durch zwei rechtwinklig gekreuzte Drahtgitter, welche aus einem vom electrischen Strome in abwechselnd entgegengesetzter Richtung durchflossenen Leitungsdraht gebildet sind. Er weist durch Rechnung und Versuche nach, wie die Wirkung aus einer anziehenden in eine abstofsende übergehe, wenn man anfangs die Gitterstäbe in der Mitte des Netzes nur ganz licht, nach den Rändern aber immer dichter gestell habe, und dann sie so verschiebe, dafs sie mehr und mehr in gleicher Vertheilung den ganzen Querschnitt überziehen. Die erstere Anordnung soll die Vertheilung der Molecularströne in magnetischen, die letztere in diamaguetischen Körpern repräsentiren.

\title{
B. Chemie.
}

a. Unorganische Chemic.

Künstliche Nachbildung krystallisirter Mineralien.

Becquerel ${ }^{*}$ ) macht darauf aufmerksam, wie die Nachbildung mebrerer krystallisirter Mineralien durch die Einleitung von sehr langsam vor sich gehenden chemischen Einwirkungen möglich ist, und wie namentlich auf electrochemischem Wege solche Resultate erreichbar sind. Unter den von ihm angewendeten Methoden, die er theilweise schon früher **) beschrieb, hebt Becquerel namentlich die folgenden hervor.

*) Compt. rend. XXXIV, 29.

*) Compt. rend. XX. 
Das eine Verfahren besteht darin, eine Auflösung von Kieselsäure oder Thonerde in Kali oder Natron in einem verschlossenen Gefüfse auf ein galvanisches Element einwirken zu lassen, welches aus einem oxydirbaren Metall und einem Draht von Kupfer oder Platin, welcher um das erstere'gewunden ist, besteht. Bei Anwendung von amalgamirtem Zink und Kupferdraht bilden sich so auf dem ersteren langsam kleine Reguläroctaëder von Zinkoxydhydrat $\mathrm{ZnO}, \mathrm{HO}$; bei Anwendung von Blei und Kupferdraht auf dem ersteren grünliche, durchsichtige, dicht verwachsene Krystalle von wasserfreiem Bleioxyd, welche nach Becquerel wahrscheinlich von einem graden rhombischen Prisma abzuleiten sind, und bei dem Zerreiben ein gelbliches Pulver geben.

Bei der Einwirkung von Schwefelblei (Bleiglanz) auf eine Lösung von schwefelsaurem Kupferoxyd und Chlornatrium schieden sich im Verlauf von sieben Jahren auf dem Bleiglanz selbst oder an den Wandungen des Gefärses ab : Chlornatrium in grofsen Krystallen; Chlorblei in schwachgelblichen Nadeln und Würfeln; schwefelsaures Bleioxyd in ähnlichen Formen, wie sie auch der natïrlich vorkommende Bleivitriol, namentlich der von Anglesea, zeigt; eine Verbindung von schwefelsaurem Bleioxyd mit Chlorblei (chlorasulfate) in Nateln; basisches Chlorblei in mikroscopischen Krystallen; schwarzes Schwefelkupfer, welches keine Andeutung von Krystallisalion zeigte. Je nach dem Verhältnils von schwefelsaurem Kupferoxyd und Chlornatrium und dem Concentrationsgrad der Lösung bildet sich das eine oder das andere dieser Producte vorzugsweise. - Aus einer mit schwefelsaurem Kupferoxyd und Chlornatrium gesättigten und dann mit dem dreifachen Volum Wasser verdünnten Auflösung, in welche ein mit Platindraht umwundenes Stück Bleiglanz eintauchte, schied sich im Lauf von 7 Jahren eine beträchtliche Menge würfelförmig krystallisirten Chlorbleies ab. Auf 
einem in dieselbe Auflösung gebrachten Stück zweifachbasischen kohlensauren Kupferoxyds (Malachits) schieden sich gleichfalls cubische Krystalle von Chlorblei ab.

In eine gesättigte Lösung von kohlensaurem Natron und kohlensaurem Kupferoxyd wurde eine mit Platindraht umwundene Bleiplatte eingelegt, und das Ganze in einem unvollsländig verschlossenen Glase während 7 Jahren sich selbst überlassen. Allmälig oxydirte sich das Blei, und das gelöste Bleioxyd wirkte auf das kohlensaure Kupferoxyd ein ; Kupferoxydhydrat und kohlensaures Bleioxyd schieden sich aus. Letzteres überzog die Bleiplatte mit kleinen Krystallen, deren Form die des natürlichen Weilsbleierzes zu seyn schien.

Gypsplatten, in eine schwache ( $2^{\circ}$ Baumé zeigende) Lösung von zweifach-kohlensaurem Natron eingetaucht, überziehen sich bald mit kleinen rhomboëdrischen Krystallen von Kalkspath (vgl. S. 203).

In einer andern Mittheilung *) bespricht Becquerel nochmals den Einflufs, welchen die Erregung electrischer Ströme auf das Zustandekommen chemischer Verbindungen ausübt. Er hebt folgenden Versuch hervor. Wird in eine Flasche Chlornatriumlösung gebracht, dann eine dünne runde Eisenscheibe, auf welcher eine Spirale aus Kupfer-oder Platindraht liegt, horizontal so eingebracht, dals sie eben mit der Chlornatriumlösung überdeckt ist, und das Ganze in einem unvollständig verschlossenen Gefälse sich selbst überlassen, so scheidet sich an der Spirale bald in rhombischen Prismen krystallisirtes kohlensaures Natron aus. In gleicher Weise können die kohlensauren Salze von Kali und mehreren Erden erhalten werden.

Durch die Einwirkung verschiedener Salzlösungen auf kohlensauren Kalk erhielt Becquerel folgende Resultate. -

*) Compt. rend. XXXIV, 573. 
Läfst man langsam, unter Mitwirkung von kohlensaurem Gas, eine Lösung von phosphorsaurem Ammoniak auf ein Stück Kalkstein einwirken, so bilden sich nach und nach an der Oberfläche des letztern grade rhombische, mit zweiflächigen Enden begrenzte Krystalle von der Zusammenselzung $2 \mathrm{CaO}$, $\mathrm{PO}_{5}, 4$ HO. - Eine Lösung ron salpetersaurem Bleioxyd oder von Chlorblei giebt bei monatelanger Einwirkung auf Kalkstein Krystalle von kohlensaurem Bleioxyd. - Bei dem Eintauchen eines Stückes groben Kalksteins in eine Lösung von salpetersaurem Kupferoxyd ron 12 bis $15^{\circ}$ Baumé entwickelt sich Kohlensäure, während zugleich sich salpetersaurer Kalk auflöst und basisch-salpetersaures Kupferoxyd sich auf dem Kalkstein und in den Poren desselben in nadelförmigen hellgrünen Kryslallen absetzt. Wird das mit solchen Krystallen besetzte Stiick Kalkstein in eine Lösung von zweifach-kohlensaurem Natron, von 5 bis 6 Aräometergraden, gebracht, so wird das basisch - salpetersaure Kupferoxyd im Laufe einiger Tage zu grünem basischem kohlensaurem Kupferoxyd (Malachit); bei allzulangem Eintauchen in die alkalische Flüssigkeit bildet sich ein himmelblaues kohlensaures Doppelsalz von Kupferoxyd und Natron. Bei Eintauchen in eine verdünnte Lösung vor kohlensaurem Kali an der Stelle von ziveifach - kohlensaurem Natron wird das basisch - salpetersaure Kupferoxyd zu Kupferoxydhydrat CuO, HO, welches dann feine blaue, dem Kalkstein fest anhängende, an der Luft sich nicht verändernde Krystalle bildet. Läfst man während mehrerer Monate ein Stück porösen Kalkstein mil einer gesittigten Lösung von schwefelsaurem Kupferoxyd in Berïhrung, so scheiden sich auf der Oberfläche des ersteren neben vielen Krystallen von schwefelsaurem Kalk kleine hellgrüne krystallinische Warzen von vierfach-basisch-schwefelsaurem Kupferoxyd aus, welche sehr dem natürlich vorkommenden (dem Brochantit) gleichen. 
Durch Einwirkung einer Lösung von zweifach-kohlensaurem Natron wird auch dieses Kupfersalz zu zweifach-basischem kohlensaurem Kupferoxyd (Malachit).

Während durch die Einwirkung einer sehr schwachen Lösung von zweifach-kohlensaurem Natron auf Gyps sich kohlensaurer Kalk in der Form von Kalkspath abscheidet (S. 201), tritt unter denselben Umständen, aber bei Anwendung einer stärkeren Lösung von zweifach-kohlensaurem Kali (Lösung von 5 bis $6^{\circ}$ Baumé) Abscheidung des kohlensauren Kalks in der Form des Arragonits ein. - Kohlensaurer Kalk mit krystallinischer Structur schied sich ab, als Gypsstücke während mehrerer Monate mit einer Kalilösung von $10^{\circ}$. Baumé in einem nicht vollständig verschlossenen Gefälse zusammengelassen wurden.

Ueber die Eigenschaften electrisirter Substanzen.

Fremy und E. Becquerel *) haben Untersuchungen über die chemischen Eigenschaften electrisirter Körper angesteHt, namentlich über den durch Einflufs der Electricität mit stärkeren oxydirenden Eigenschaften begabten Sauerstoff, das s. g. Ozon. Die Endergebnisse ihrer Versuche sind im Folgenden entbalten.

Die durch Schönbein und Marign ac über den mittelst Electricität ozonisirten Sauerstoff gemachten Angaben wurden bestätigt. Der durch electrische Zerlegung des Wassers erbaltene Sauerstoff enthielt indels, selbst wenn er den eigenthümlichen Geruch in hohem Grade besals, nur eine sehr kleine Menge des wirksamen Princips, und das Volum

*) Ann. chim. phys. [3] $\mathrm{XXXV}, 62$. 